\title{
Deconstruction of prior knowledge and visual narratives in Computing pedagogy
}

\author{
Jamil, Md Golam ${ }^{\text {a }}$ and Isiaq, Sakirulai Olufemi ${ }^{\text {b }}$
}

${ }^{\mathrm{a}}$ Solent Learning and Teaching Institute, Solent University, UK, ${ }^{\mathrm{b}}$ School of Media Arts and Technology, Solent University, UK.

\begin{abstract}
Evaluating students' prior knowledge, particularly in higher education, has been a difficult task due to lack of any known reliable technique. This paper describes a research that involved a technology-enhanced approach for collecting prior knowledge data and presented those through visual narratives. The use of visual narratives is new in the research within engineering discipline, particularly in Computing. The study took place at a British university where forty five Computing students participated in the data collection process. The students were asked questions about their concepts around certain topics, academic interests, and assessment preferences. Data were collected using an online audience reply and analysis tool, Mentimeter, which also generated real time visuals, such as word clouds and graphs, based on the student responses. Several narratives were composed upon the findings depicted through the visuals. The key contribution of the research is a unique prior knowledge data analysis procedure which is convenient and effective in deciding pedagogic principles.
\end{abstract}

Keywords: Prior knowledge; Deconstruction; Visual narrative; Computing; Technology-enhanced 


\section{Introduction}

Historically, higher education is dominated by conventions (Gibbs, 2015). Many higher educational institutions follow top-down approaches where students' knowledge, experience and expertise are bypassed in the planning and delivery of teaching (Henderson \& Dancy, 2008). Besides, teachers are often led by personal learning experiences and workplace mentors, which compel them to continue the ongoing teaching tradition without any modification (Sugrue, 1997). Insufficient professional training and limited teaching preparation time also force them to blindly follow conventional content choices and pedagogic approaches (Johnson et al., 2012). As a result, teaching and assessment often do not reflect students' prior knowledge. However, learning, particularly in higher education, is a dynamic journey that requires an amalgamation of students' educational experience, motivation, and prior and new knowledge (Kolb \& Kolb, 2005).

\section{Importance of linking prior knowledge}

Prior knowledge is the learners' knowledge base at the time of new and relevant knowledge acquisition (Biemans \& Simons, 1996). A knowledge base may include learning strategies, known concepts, learning related expectations, and interaction with surrounded environment (Nasir \& Hand 2006). In higher education, learners' prior knowledge of academic concepts and learning strategies that were developed in their early educational stages play an important role (Schmidt et al., 2017).

Importance of linking prior knowledge with teaching and learning is twofold. First, it can help determine students' learning achievements and shape their learning strategies (Hailikari et al., 2007). Second, it can capture students' learning behaviours and processes which educators may use to design suitable pedagogic plans (Schoenfeld, 2000). However, prior knowledge can accelerate or hinder new knowledge and learning, thus failing to evaluate its quality may result into unsuccessful instructional designs (Ambrose et al., 2010).

\section{Problems of assessing prior knowledge}

Researchers acknowledge the importance of prior knowledge, but any viable measuring approach has not been extensively discussed (Oleson \& Hora, 2014). Although standardised assessment and self-evaluation techniques are used in formal education to evaluate students' prior knowledge, often they fail to provide a holistic scenario of learner groups (Posselt, 2016). Therefore, educational researchers suggest for new assessment methods (Anderson, 1995). This study involved a unique technology-enhanced approach to collect prior knowledge data and deconstructed those through visual narratives. 


\section{The study}

Our study took place at a British university that prioritises student engagement, learning experience and employability. A representation of working class is high in the student population and many students are the first from their family to attend a university.

We explored prior knowledge of the students studying in an undergraduate Computing course. The key learning areas were computing fundamentals, software engineering and software project management. The students came from different academic backgrounds, for example some with low grades from previous educational stages, some with industry experience, and a high number of students from other countries.

We followed a qualitative approach involving visual narratives where we collected data using Mentimeter (www.mentimeter.com), an online audience reply and analysis tool. 'Narratives' are the explicit stories of human experiences, objects or cultural contexts (Clandinin \& Connelly, 2000). Visual narratives are the narratives based on pictorial depiction or references, such as historical records, films and photographs (Cobley, 2013).

\subsection{Research questions}

The overarching aim of our research was to explore the viability of visual narrative approach in analysing students' prior knowledge. We also studied the feasibility of technology-supported data collection technique from students in traditional university classes.

RQ1 To what extent do visual data illuminate students' prior knowledge?

RQ2 To what extent is the quality of prior knowledge classifiable?

RQ3 How does students' prior knowledge help decide pedagogic principles?

\subsection{Methodology}

Narrative research is common in social sciences and humanities (Squire et al., 2014), but the approach is yet to be adopted in engineering disciplines. In this study, we composed several narratives based on visuals, such as word clouds and graphs. We asked the students questions about their concepts around certain topics, academic interests, and assessment preferences. The importance of addressing these areas of prior knowledge has been discussed in the educational literature including Rodger et al. (2015) and Kahu et al. (2015).

Research participants: Forty five Computing students participated in the data collection process. All of them gave consent for voluntary participation in the research and we obtained an ethics approval from the University. We collected data in regular weekly sessions across the semester and student participation varied in different sessions.

Data collection procedure: The students responded to questions and provided short answers via online system, Mentimeter, from their personal computer or smartphones. We, the researchers, retrieved the responses in real time in the form of visuals. Finally, we 
deconstructed the visuals and narrated them explicitly. The validity and reliability of the data were high as they were anonymous and real time. Additionally, the possibility of human errors in data processing was minimum because the data were automated.

\section{Findings}

For a prior knowledge specific discussion, we considered three relevant areas of focus, namely students' academic interests, conceptual understanding, and assessment experience. We are including the relevant visuals in the first narrative as an example in Figure 1.

\subsection{Visual Narrative: academic interests}

\section{a) Questions}

- In no more than three words, what are the attributes/skills of a good learner?

- What methods of learning are you aware of, maximum three words?

- State any three skills required for a quality final year project.

- In no more than three terms, give your understanding of a quality final year project.

\section{b) Visuals: word clouds}

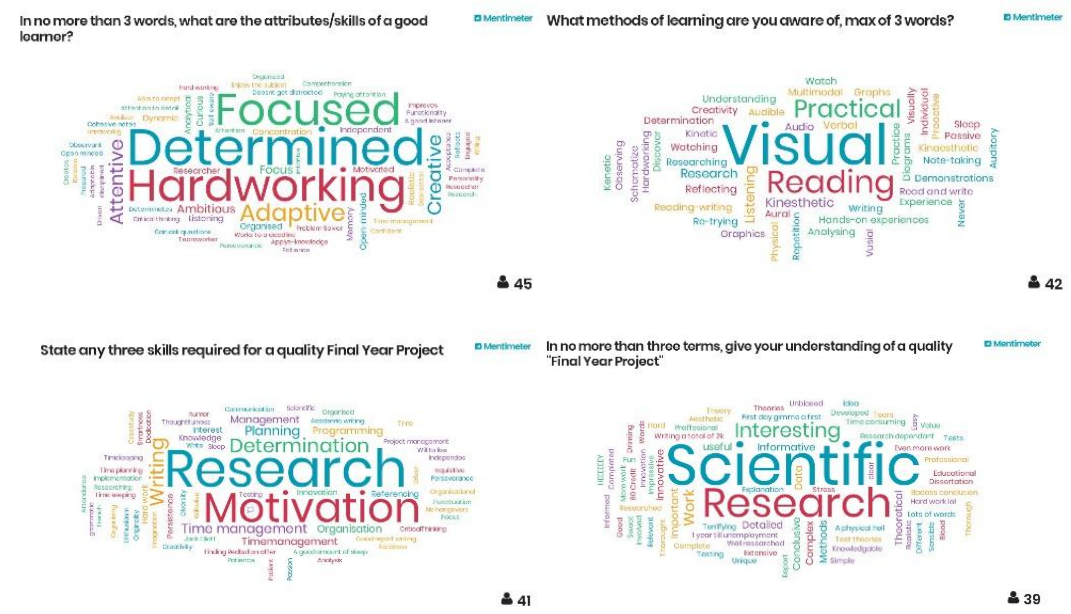

Figure 1. Visuals (word clouds) of students' academic interests

The responses of the questions reflected the students' views on learning strategies and associated skills necessary for becoming a successful learner. The opinions were diverse and thus indicated varied perceptions about effective learning skills and strategies. First, the majority of the students considered that a successful learner needs to be determined, hardworking and focused. Some students also mentioned creativity, adaptiveness and alternative thinking as essential attributes for learning effectively. Second, the most popular learning strategies among the students were visual, practical and reading activities. Preferences for reflection, research, demonstration and hands-on experience were also 
mentioned in this aspect. Regarding the final year project, the students believed they would require research skills and higher motivation to effectively perform in this module. A few students also stated the importance of task-organisation, time management and writing for projects. Finally, while expressing opinions about the quality of final year project the students mentioned that the work needs to be scientific, research-based and interesting. Some students also suggested for informative, complex, and theoretical features to enhance quality of work.

\section{c) Pedagogic guidelines}

The students of the Computing course are generally well aware of the requirements of a university level academic programme. They seem to be well prepared for complex and challenging teaching/ learning activities. As many of them emphasised the need for including research elements in the project work; exploratory, experimental and critical analysis based activities will be suitable for them. The students will enjoy multimedia and reading based learning activities. A few practical sessions can also be arranged to enhance their learning. Consequently, it is indicative (for tutors and learners) that teaching materials and pedagogic activities should harmonise multiple learning strategies to carry along all students, particularly for a specific cohort.

\subsection{Visual Narrative: conceptual understanding}

\section{a) Questions}

- Computers only perform calculations and nothing else, True, False or Unsure?

- If computer performs only calculations and nothing else, how is it done?

- If computer perform other activities apart from calculations, what are these activities and how is it done?

\section{b) Visuals: word clouds and graphs}

Developing computer programs requires a higher understanding of computer fundamentals and principles. Not only does this guide the students in knowing how to prepare codes in a computer relatable manner but help with informed decisions and actions in terms of components and processes of computing devices. Knowing the breadth of students' requisite knowledge guides tutors on how best to introduce intended topics. The aims of the aforementioned questions in this case were to check the students' knowledge about the definition of a computing device, and if their answers were just assumptions or constructed upon pertinent prior knowledge. More than three-fourth of the students gave a wrong answer of the first question whereas a very small number was unsure. While responding to the second question most of the students mentioned 'do not know' and 'unsure'. There were some explanatory answers, such as 'calculating data through binary code', 'using binary to code and break down into a language it can understand and then figure it out', and 'computer does not only perform calculations' for this question. A particular response was 'if all data is processed in binary, we could say manipulating these numbers, computer only 
performs calculations'. This confirmed the respondent's proper understanding of the topic. There were a variety of student answers for the question three, which include 'do not know how it is done', 'rendering video', 'process memory cache', 'read and write from disk' and 'editing, storing pictures'. Similar to question two, there was a single correct response which is 'they do not perform other activities'.

\section{c) Pedagogic guidelines}

Concepts about computing devices and types may seem trivial particularly for Computing students who have a common belief that they already know everything about these devices at higher level. Additionally, they may have an enhanced confidence about these concepts as they make use of these devices on daily basis. However, in this particular cohort, a significant proportion of students do not have a concrete understanding of the intended subject matter, particularly on how computer operations are being carried out. Therefore, at the initial stage, it is imperative for tutors to systematically evaluate students' knowledge and facilitate adequate understanding of the definitions of computing devices including how operational activities are carried out.

\subsection{Visual Narrative: assessment experience}

\section{a) Questions}

- In no more than three words, why is assessment necessary in this unit?

- In no more than three words, when does an assessment activity help you learn better?

- Choose three assessment techniques that you consider the most effective.

\section{b) Visuals: word clouds and graphs}

Students gave varying opinions about the necessity of assessment, qualities of assessment tasks, and the assessment schemes they prefer. There are several comparable and distinct perceptions describing their prior knowledge and experience with assessment techniques. First, there were dissimilarities in the students' perceptions about the necessity of assessment. Many of them considered assessment as a means of gaining knowledge for understanding certain topics, while some considered it as an enabler to progress in their higher education journey. Interestingly, a few students mentioned teamwork indicating the need for promoting collaboration between peers, and tutors. Second, in terms of the useful qualities of assessment tasks, both independent and team efforts were mentioned as requirements. Surprisingly, some students shared that challenging and stressful assessment tasks helped them learn better. Third, students reflected on their preferences about effective assessment tasks. They generally considered project, portfolio, group presentation and short essays as most effective. Some students mentioned their preference for quiz/test. However, long essay and individual presentation were not in their preference list. 


\section{c) Pedagogic guidelines}

Assessment schemes in this module will require combining both collaborative and independent tasks. Students will positively accept challenging assessments if they provide rich and dynamic learning experience. However, many students may not find the commonly used assessment techniques, such as long essay and individual presentation worthwhile. Therefore, if tutors plan to use these assessment schemes (should it be most suitable), they will have to equip and motivate students with the benefits of these type of assessment.

\section{Lessons learned}

\section{a) Methodology transfer provides new insights into disciplinary research}

The use of visual narratives to identify educational perspectives in engineering discipline is unique. Narrative research methodology detailed in this study shows potentials in evaluating the quality of students' prior knowledge in computing subjects. This demonstrates a successful transfer of methodological paradigm to an unexplored academic discipline.

\section{b) Use of technology is viable in collecting prior knowledge data}

Collecting and analysing students' prior knowledge data are complex and time consuming tasks. An appropriate systematic application of technology can enhance the narrative approach of deconstructing visuals which has been found convenient, reliable and effective.

\section{c) Quality of questions may determine the breadth and depth of narration}

Student responses were based on the tutor's questions, thus may have been guided. Therefore, the construction of these questions requires following careful and effective approaches. Considering the volume of students' contribution and its relevance to understanding prior knowledge, the questions may need to be simple and communicative. Two types of questions have been adopted in this research: (i) direct questions, for example 'computer only performs calculations, true, false or unsure?' to know students' levels of conceptual knowledge, and (ii) probing questions, for example 'why is assessment necessary in this unit?' to understand logics and opinions of the students.

\section{d) Deconstruction of prior knowledge can help decide pedagogic principles}

A careful composition of visual narratives can provide an in-depth orientation to students' learning capacity, interests and attitudes. The visuals are based on quantitative data, thus it is possible to classify the levels of students' prior knowledge. This detailed information can help tutors consider pedagogy and assessment related decisions in a holistic manner. The data collection and visual generation are prompt, so any rapid pedagogic change or modification may be possible in the approach. A follow up of this research is the development of a 'technology-enhanced and prior knowledge informed pedagogic framework' which can potentially improve teaching and learning experiences. 


\section{References}

Ambrose, S. A., Bridges, M. W., DiPietro, M., Lovett, M. C., \& Norman, M. K. (2010). How learning works: Seven research-based principles for smart teaching. John Wiley \& Sons.

Anderson, J.R. (1995). Cognitive psychology and its implications (5th ed.). New York: Wroth.

Biemans, H. J., \& Simons, P. R. J. (1996). CONTACT-2: A computer-assisted instructional strategy for promoting conceptual change. Instructional Science, 24(2), 157-176.

Clandinin, D. J., \& Connelly, F. M. (2000). Narrative inquiry. Wiley.

Cobley, P. (2013). Narrative. Routledge.

Gibbs, G. (2015). 53 Powerful Ideas. Retrieved on 16 January 2018 from https://www.seda.ac.uk/53-powerful-ideas

Hailikari, T., Nevgi, A., \& Lindblom-Ylanne, S. (2007). Exploring alternative ways of assessing prior knowledge, its components and their relation to student achievement: A mathematics based case study. Studies in Educational Evaluation, 33(3-4), 320-337.

Henderson, C., \& Dancy, M. H. (2008). Physics faculty and educational researchers: Divergent expectations as barriers to the diffusion of innovations. American Journal of Physics, 76(1), 79-91.

Johnson, S. M., Kraft, M. A., \& Papay, J. P. (2012). How context matters in high-need schools: The effects of teachers' working conditions on their professional satisfaction and their students' achievement. Teachers College Record, 114(10), 1-39.

Kahu, E., Stephens, C., Leach, L., \& Zepke, N. (2015). Linking academic emotions and student engagement: Mature-aged distance students' transition to university. Journal of Further and Higher Education, 39(4), 481-497.

Kolb, A. Y., \& Kolb, D. A. (2005). Learning styles and learning spaces: Enhancing experiential learning in higher education. Academy of management learning \& education, 4(2), 193-212.

Nasir, N. I. S., \& Hand, V. M. (2006). Exploring sociocultural perspectives on race, culture, and learning. Review of Educational Research, 76(4), 449-475.

Oleson, A., \& Hora, M. T. (2014). Teaching the way they were taught? Revisiting the sources of teaching knowledge and the role of prior experience in shaping faculty teaching practices. Higher Education, 68(1), 29-45.

Posselt, J. R. 2016. Inside Graduate Admissions: Merit, Diversity, and Faculty Gatekeeping. Cambridge, MA: Harvard University Press.

Rodger, S., Turpin, M., \& O'Brien, M. (2015). Experiences of academic staff in using threshold concepts within a reformed curriculum. Studies in Higher Education, 40(4), 545-560.

Schmidt, H. K., Rothgangel, M., \& Grube, D. (2017). Does prior domain-specific content knowledge influence students' recall of arguments surrounding interdisciplinary topics?. Journal of adolescence, 61, 96-106.

Schoenfeld, A. H. (1999). Models of the teaching process. The Journal of Mathematical Behavior, 18(3), 243-261. 
Squire, C., Andrews, M., Davis, M., Esin, C., Harrison, B., Hyden, L. C., \& Hyden, M. (2014). What is narrative research?. Bloomsbury Publishing.

Sugrue, C. (1997). Student teachers' lay theories and teaching identities: Their implications for professional development. European Journal of Teacher Education, 20(3), 213-225. 